\title{
Suppression of STAT5b in pancreatic cancer cells leads to attenuated gemcitabine chemoresistance, adhesion and invasion
}

\author{
HIROKI SUMIYOSHI ${ }^{1}$, AKIRA MATSUSHITA ${ }^{1}$, YOSHIHARU NAKAMURA ${ }^{1}$, \\ YOKO MATSUDA $^{2}$, TOSHIYUKI ISHIWATA ${ }^{2}$, ZENYA NAITO $^{3}$ and EIJI UCHIDA ${ }^{1}$ \\ ${ }^{1}$ Department of Gastrointestinal and Hepato-Biliary-Pancreatic Surgery, Nippon Medical School, Tokyo; \\ ${ }^{2}$ Department of Pathology, Tokyo Metropolitan Geriatric Hospital and Institute of Gerontology, Tokyo; \\ ${ }^{3}$ Department of Integrated Diagnostic Pathology, Nippon Medical School, Tokyo, Japan
}

Received December 23, 2015; Accepted March 8, 2016

DOI: $10.3892 /$ or.2016.4727

\begin{abstract}
Pancreatic ductal adenocarcinoma (PDAC) is one of the most lethal solid malignancies, and there is an urgent need for new therapeutic strategies based on the molecular biology of PDAC. Signal transducers and activators of transcription 5 (STAT5) are known to be activated in a variety of malignancies and involved in tumor proliferation, apoptosis, and invasion, whereas the expression and biological role of STAT5b in PDAC are less clearly defined. In the present study, we examined the expression and role of STAT5b in human pancreatic cancer cell lines. Expressions of STAT5b mRNA and protein were detected in eight kinds of pancreatic cancer cells. Confocal microscopy and western blot analysis indicated that STAT5b is localized in both cytoplasm and nuclei. Immunoprecipitation analysis revealed tyrosine phosphorylation of STAT5b in pancreatic cancer cells. These results indicate that STAT5b in pancreatic cancer cells is constitutively activated. STAT5b shRNA clones in PANC-1 cells, which express relatively high levels of STAT5b, exhibited reduced chemoresistance against gemcitabine, adhesion and invasion compared to sham. On the other hand, AsPC-1 and BxPC3 cells, which express relatively low levels of STAT5b, exhibited reduced chemoresistance compared to PANC-1 cells. Moreover, STAT5b overexpression clones in AsPC-1 cells exhibited increased chemoresistance compared to sham. STAT5b shRNA clones in PANC-1 cells were more sensitive to the proapoptotic actions of gemcitabine, as evidenced by PARP and cleaved caspase-3 activation. Gemcitabine also significantly reduced Bcl-xL levels in the STAT5b shRNA-expressing cells. We also investigated the clinicopathological characteristics of STAT5b expression of
\end{abstract}

Correspondence to: Dr Akira Matsushita, Department of Gastrointestinal and Hepato-Biliary-Pancreatic Surgery, Nippon Medical School, 1-1-5 Sendagi, Bunkyo-ku, Tokyo 113-8603, Japan E-mail: akira-matsushita@nms.ac.jp

Key words: pancreatic ductal adenocarcinoma, signal transducers and activators of transcription $5 \mathrm{~b}$, gemcitabine chemoresistance, Bcl-xL, invasion, adhesion
PDAC. Although a significant correlation between STAT5b expression and overall survival rates was not observed, a significant correlation with main pancreatic duct invasion was observed. These findings suggest that STAT5b confers gemcitabine chemoresistance and promotes cell adherence and invasiveness in pancreatic cancer cells. Targeting STAT5b may lead to novel therapeutic strategies for PDAC.

\section{Introduction}

Pancreatic ductal adenocarcinoma (PDAC) is one of the most lethal solid malignancies and the fourth leading cause of cancer-related death (1). Surgical resection is the only potentially curative treatment. However, most patients present with advanced disease stages and are not candidates for surgery at the time of diagnosis due to the presence of distant metastases, peritoneal seeding, or invasion into adjacent vital structures $(2,3)$. For a decade, gemcitabine is the standard chemotherapy for advanced PDAC (4). Most significant problem of gemcitabine treatment for PDAC is the chemoresistance. Although several studies reported that upregulation or downregulation of the multiple membrane transporters, enzymes involved in the metabolism of gemcitabine and alterations in the apoptotic pathways may confer sensitivity and resistance (5), the overall survival remains dismal with chemotherapy using gemcitabine. Therefore, there is an urgent need for new therapeutic strategies which could overcome the chemoresistance to gemcitabine in PDAC.

The Janus kinase/signal transducer and activator of transcription (JAK/STAT) pathway is known as one of the key pathways that affect cell growth, proliferation and survival in many human cancers $(6,7)$. The STAT family members (seven members comprising STAT1, STAT2, STAT3, STAT4, STAT5a/5b and STAT6) play dual roles as cytoplasmic signaling proteins and as nuclear transcription factors $(6,8)$. Critical interactions leading to modulation of STAT activity may occur in the cytoplasm where: JAK kinases, coupled to cytokine receptors, phosphorylate STAT, thereby promoting nuclear translocation. Furthermore, JAK-mediated STAT phosphorylation leads to the formation of stable homodimers and heterodimers, resulting in their nuclear translocation (9). Once in the nucleus, STAT molecules bind specific promoter 
DNA sequences causing gene transcription that regulates cell proliferation, differentiation and apoptosis (10).

Of these STAT members, STAT3 has been frequently identified by its constitutive activation in many human cancers, including pancreatic cancer $(7,11,12)$. In addition to STAT3, STAT5 has also been implicated in several cancers for tumor proliferation, apoptosis and invasion $(7,9)$. STAT5 has two highly homologous isoforms, STAT5a and STAT5b. STAT5a was originally identified as a mammary gland factor that augments milk protein expression on prolactin induction (13) and has been reported to be associated with breast $(14,15)$ and prostate cancer $(16,17)$. STAT5b, which is highly homologous with STAT5a at the amino acid level, has been associated with advanced tumor stages, venous infiltration, and poor prognosis in hepatocellular carcinoma (18); with tumor size in lung cancer (19); with TNM stage in colorectal cancer (20) and with tumorigenesis and progression in glioblastoma multiforme (21). As for pancreatic diseases, STAT5 has been reported to be associated with diabetes mellitus (22) and activated STAT5b (but not STAT5a) was found in intraductal papillary mucinous neoplasm (IPMN) but not in benign adenomas (23). In contrast, the expression and biological role of STAT5b in PDAC are less clearly defined. We, therefore, hypothesized that elucidating the biological role of STAT5b in PDAC may pave the way for novel therapeutic options in treating pancreatic cancer.

In the present study, we examined the expression and activation of STAT5b in human pancreatic cancer cell lines. We downregulated STAT5b with shRNA in human pancreatic cancer cells and investigated the effect of STAT5b suppression on reducing cell growth, gemcitabine chemosensitivity, apoptosis, invasion and adhesion. We also investigated the clinicopathological characteristics of STAT5b expression in PDAC.

\section{Materials and methods}

Antibodies. The following items were purchased: anti-STAT5a (sc1081) rabbit polyclonal antibodies, anti-STAT5b (sc1656) mouse monoclonal antibodies, and anti-phosphotyrosine (sc7020) mouse monoclonal antibodies from Santa Cruz Biotechnology (Santa Cruz, CA, USA); Alexa Fluor 488 goat anti-mouse IgG (A-11001), Hoechst 33258, pentahydrate (bisbenzimide), and anti-V5 Tag (\#46-0705) mouse monoclonal antibodies from Invitrogen (Life Technologies; Carlsbad, CA, USA); anti-lamin B1 (ab16048) rabbit polyclonal antibodies from Abcam plc (Cambridge, UK); anti-PARP (\#9542) rabbit polyclonal antibodies, anti-cleaved caspase-3 (\#9664) rabbit monoclonal antibodies, and anti-Bcl-xL (\#2746) rabbit monoclonal antibodies from Cell Signaling Technology (Danvers, MA, USA); and anti- $\beta$-actin (A1978) mouse monoclonal antibodies from Sigma-Aldrich (St. Louis, MO, USA).

Reagents. The following items were purchased: fetal bovine serum (FBS), DMEM, RPMI, MEM and trypsin solution from Gibco (Life Technologies); RNeasy Mini kit from Qiagen (Hilden, Germany); High Capacity RNA-to-cDNA kit from Applied Biosystems (Darmstadt, Germany); NE-PER Nuclear and Cytoplasmic Extraction reagents and SuperSignal West Pico and Femto chemiluminescent substrates from
Thermo Fisher Scientific (Rockford, IL, USA); FuGENE HD Transfection reagent from Promega (Madison, WI, USA); G418 (Geneticin) from Roche Diagnostics Deutschland GmbH (Mannheim, Germany); laminin, collagen from human placenta type IV [(collagen IV) from Sigma-Aldrich]; Cell Counting kit-8 from Dojindo Laboratories (Kumamoto, Japan); BioCoat Matrigel Invasion Chamber ( $8-\mu \mathrm{m}$ pore size) and fibronectin from BD Biosciences (Franklin Lakes, NJ, USA); gemcitabine hydrochloride from Wako Pure Chemical Industries (Osaka, Japan); Fluorescent Mounting Medium from Dako Japan (Tokyo, Japan); Histofine Simple Stain Max PO (M) or (R) kit from Nichirei Biosciences, Inc., (Tokyo, Japan); and recombinant human epidermal growth factor (EGF, 236-EG) and recombinant human platelet-derived growth factor (PDGF, 220-BB) from R\&D Systems (Minneapolis, MN, USA).

Pancreatic cancer cell lines. AsPC-1, BxPC3, Capan-1, HPAF-2, MIA PaCa-2, PANC-1 and SW1990 PDAC cell lines were purchased from the American Type Culture Collection and the PK-45H cell line was obtained from the Cell Resource Center for Biomedical Research, Institute of Development, Aging and Cancer, Tohoku University.

Cell culture. PANC-1, MIA PaCa-2 and SW1990 cells were grown in DMEM, AsPC-1, Capan-1, BxPC3 and PK-45H cells were grown in RPMI, and HPAF-2 cells were grown in MEM. All of the cultures were supplemented with $10 \% \mathrm{FBS}$, $100 \mathrm{units} / \mathrm{ml}$ penicillin, $100 \mu \mathrm{g} / \mathrm{ml}$ streptomycin and $250 \mathrm{ng} / \mathrm{ml}$ amphotericin B. Cells were maintained at $37^{\circ} \mathrm{C}$ in a humid atmosphere with $5 \% \mathrm{CO}_{2}$.

Quantitative RT-PCR analysis. To evaluate the STAT5b expression levels in the pancreatic cancer cell lines, TaqMan quantitative RT-PCR was performed. Total RNA was isolated with RNeasy Mini kit according to the manufacturer's protocol. For cDNA synthesis, the High Capacity RNA-to-cDNA kit was used according to the manufacturer's protocol. Quantitative RT-PCR was performed using the 7500 Fast Real-Time PCR System (Applied Biosystems, Darmstadt, Germany) and for evaluation, commercial TaqMan ${ }^{\circledR}$ Gene Expression- assays (Applied Biosystems, AoD, Assay-ID: Hs00273500_m1 for the studied genes STAT5b and Hs02758991_g1 for GAPDH as the reference gene) were used with optimized primer and probe concentrations.

Protein extraction and western blot analysis. To extract protein from cell lines, cells were washed twice with cold PBS and reacted with lysis buffer Triton X-100 at $4^{\circ} \mathrm{C}$ for $30 \mathrm{~min}$. After the reaction, cells were harvested by cell scraping and centrifuged at $4^{\circ} \mathrm{C}$ and $15,000 \mathrm{rpm}$ for $30 \mathrm{~min}$. For western blot analysis, $20 \mu \mathrm{l}$ of each protein was separated by gel electrophoresis on a polyacrylamide gel and transferred to nitrocellulose membranes. The membranes were blocked with Tris-buffered saline containing $0.1 \%$ Tween-20 (TBST) and 5\% skim milk, then incubated overnight at $4^{\circ} \mathrm{C}$ with the indicated primary antibodies and then for $60 \mathrm{~min}$ with the corresponding horseradish-conjugated secondary antibodies. The membranes were washed twice with TBST and incubated with goat antimouse or anti-rabbit IgG-horseradish peroxidase conjugated secondary antibodies for $1 \mathrm{~h}$ at $4^{\circ} \mathrm{C}$. The blots were washed 
three times with TBST and an enhanced chemiluminescence system (ImageQuant LAS 4000 mini; GE Healthcare Japan, Tokyo, Japan) was used to detect the bands. The band densities of PARP and Bcl-xL were measured with ImageJ (National Institutes of Health, Bethesda, MD, USA), and densitometry analysis was performed as previously described (24).

Immunofluorescence and confocal analysis. Cells were plated onto chamber slides and allowed to adhere overnight. Slides were fixed for $10 \mathrm{~min}$ in $2 \%$ paraformaldehyde and free aldehydes were quenched with $50 \mathrm{mM} / 1 \mathrm{NH}_{4} \mathrm{Cl}$ in PBS for $10 \mathrm{~min}$. Then, the cells were permeabilized in $0.1 \%$ Triton $\mathrm{X}-100$ in PBS-2\% BSA for $15 \mathrm{~min}$. Slides were then incubated at $23^{\circ} \mathrm{C}$ for $1 \mathrm{~h}$ with anti-STAT5b antibody (in 1:50 dilution). After washing with PBS, slides were incubated for $30 \mathrm{~min}$ with Alexa Fluor 488-conjugated goat anti-mouse secondary antibody (in 1:500 dilution), and the nuclei were counterstained with $0.2 \mu \mathrm{g} / \mathrm{ml} \mathrm{Hoechst} 33258$ dye for $1 \mathrm{~min}$ at $23^{\circ} \mathrm{C}$, as per a previously reported method (25). Slides were next washed 3 times in PBS and then mounted in a fluorescent mounting medium. Immunofluorescence scans were taken with a Nikon TE2000-E inverted fluorescence microscope system equipped with a Nikon Digital Eclipse C1 laser scanning confocal microscope (Nikon, Tokyo, Japan).

Cell fractionation and immunoprecipitation. Cell fractionation was carried out utilizing NE-PER Nuclear and Cytoplasmic Extraction reagents according to the manufacturer's protocol. Preparation of cell lysates and western blotting were performed as described above with primary antibodies against STAT5b (in 1:500 dilution) and against lamin B1 (1:10,000 dilution).

For immunoprecipitation, a total of $1 \mathrm{mg}$ of cell lysate was incubated overnight at $4^{\circ} \mathrm{C}$ against STAT5b antibody followed by 2 -h incubation with protein A/G plus agarose, as per a previously reported method (23). The beads were then washed three times with TBST, then boiled and subjected to western blotting as described above with primary antibodies against phosphotyrosine (1:500 dilution) and STAT5b (1:500 dilution).

Constructions and transfection of expression plasmids. To construct expression vectors for human STAT5b short hairpin (sh) RNA containing the sense target sequence for STAT5b (5'-GGA CAC AGA GAA TGA GTT A-3'), the antisense target sequence was synthesized and inserted into a pBAsihU6 Neo DNA vector. Likewise, the scrambled sequence (5'-TCT TAA TCG CGT ATA AGG C-3') was used to construct the sham vectors that served as negative controls. PANC-1 cells $\left(2 \times 10^{6}\right.$ cells/well) were plated on a $10-\mathrm{cm}$ plate and grown in DMEN medium at $37^{\circ} \mathrm{C}$. Transfection of STAT5b shRNA expression vectors and sham vectors was performed using FuGENE HD Transfection reagent according to the manufacturer's instructions, whereby $2 \times 10^{6}$ cells/well were transfected with $19 \mu \mathrm{g}$ of DNA using FuGENE HD and cells were passaged and cultured with $500 \mu \mathrm{g} / \mathrm{ml}$ of G418. Cell lysates were collected and protein levels were measured by western blotting in the same manner as described above. In order to construct the STAT5b overexpression clones, the STAT5b full-length cDNA was subcloned into pcDNA3.1/V5-His TOPO vector, which expresses a V5 tag fusion protein. Authenticity was confirmed by sequencing. AsPC- 1 cells $\left(2 \times 10^{6}\right.$ cells/well) were transfected with FuGENE HD Transfection reagent and stably transfected clones were selected with $800 \mu \mathrm{g} / \mathrm{ml}$ of G418 in RPMI. Individual clones were isolated, and expression of the V5-tagged STAT5b protein was determined by western blotting with anti-STAT5b and anti-V5 Tag antibodies as described above.

Cell proliferation assay. To assess cell proliferation, cells were seeded in a 96-well plate at a density of $8.0 \times 10^{3}$ cells/well in DMEN and incubated at $37^{\circ} \mathrm{C}$ for 24,48 or $72 \mathrm{~h}$. After the indicated time, the medium was replaced with fresh DMEN and $10 \mu \mathrm{l}$ of Cell Counting kit- 8 was added to the wells. The plate was incubated for $2 \mathrm{~h}$ at $37^{\circ} \mathrm{C}$ followed by an absorbance measurement of the wells at $450 \mathrm{~nm}$ using a microtiter plate reader. Analysis was performed in triplicate.

Sensitivity of the antineoplastic agents. To assess cell proliferation after treatment with the antineoplastic agent, $8.0 \times 10^{3}$ cells were seeded in a 96-well plate in DMEN and incubated at $37^{\circ} \mathrm{C}$ for $24 \mathrm{~h}$ similarly to the cell proliferation assay. After incubation, the medium was replaced with $100 \mu \mathrm{l}$ of $0.1 \%$ BSA containing $0,10,100$ or $1,000 \mu \mathrm{M}$ of gemcitabine reagent and incubated at $37^{\circ} \mathrm{C}$ for 48 or $72 \mathrm{~h}$. After treatment with gemcitabine for the indicated time, the medium was changed to $10 \mu \mathrm{l}$ of Cell Counting kit- 8 . Absorbance measurements at $450 \mathrm{~nm}$ were taken after $2 \mathrm{~h}$ of incubation with a microtiter plate reader. Analysis was performed in triplicate.

Apoptosis assay. PARP and cleavage of caspase-3 were monitored to assess apoptosis. After treatment with absence or presence of $1,000 \mu \mathrm{M}$ gemcitabine for $72 \mathrm{~h}$ at $37^{\circ} \mathrm{C}$, protein extraction and western blotting (as described above) were performed with antibodies against PARP (in 1:1,000 dilution), cleaved caspase-3 (in 1:1,000 dilution) and $\beta$-actin (in 1:10,000 dilution).

Adhesion assay. Adhesion assay was performed as per a previously reported method with some modification (26). Cells were suspended in serum-free medium containing $0.1 \%$ BSA and were seeded at a density of $3 \times 10^{4}$ cells/plate on non-adhesive NUNC 96-well culture plates (Thermo Fisher Scientific) coated with fibronectin, laminin or collagen IV. The cells were then incubated for $3 \mathrm{~h}$ at $37^{\circ} \mathrm{C}$ and washed with PBS. Adherent cells were fixed in $50 \mu \mathrm{l}$ of $96 \%$ ethanol for $10 \mathrm{~min}$, stained with $50 \mu \mathrm{l}$ of $0.1 \%$ crystal violet, rinsed with water and dried at room temperature for $30 \mathrm{~min}$. Stained cells were solubilized with $50 \mu \mathrm{l}$ of $0.2 \%$ Triton $\mathrm{X}-100$ and absorbance was measured at $595 \mathrm{~nm}$ with a microtiter plate reader. Adhesion assays were performed in triplicate.

Invasion assay. The invasiveness of stable transfected PANC-1 cells was measured as per a previously reported method with some modification (27). Cells $\left(2.5 \times 10^{4}\right.$ in quantity) were suspended in $500 \mu \mathrm{l}$ of serum-free medium [0.1\% bovine serum albumin (BSA)] and placed onto the upper compartment of Matrigel-coated Transwell chambers $(8-\mu \mathrm{m}$ pore size, BioCoat Matrigel Invasion Chambers; Becton-Dickinson Labware). The lower compartment was filled with $750 \mu \mathrm{l}$ of medium containing 1\% FBS, $1 \mathrm{nM}$ EGF or $1 \mathrm{nM}$ PDGF. After $20 \mathrm{~h}$, 
Table I. No correlation of clinicopathological characteristics and STAT5b expression in pancreatic cancer.

\begin{tabular}{|c|c|c|c|c|}
\hline Variables & No. & STAT5b-strong & STAT5b-weak & P-value \\
\hline \multicolumn{5}{|l|}{ Gender } \\
\hline Male & 27 & 9 & 18 & \\
\hline Female & 17 & 5 & 12 & NS \\
\hline \multicolumn{5}{|l|}{ Age (years) } \\
\hline$<65$ & 14 & 4 & 10 & \\
\hline$\geq 65$ & 30 & 10 & 20 & NS \\
\hline \multicolumn{5}{|l|}{ UICC } \\
\hline N0 & 18 & 6 & 12 & \\
\hline N1 & 26 & 8 & 18 & NS \\
\hline \multicolumn{5}{|l|}{ UICC stage } \\
\hline IA/IB/II A & 18 & 6 & 12 & \\
\hline IIB/III/IV & 26 & 8 & 18 & NS \\
\hline \multicolumn{5}{|c|}{ Main pancreatic duct invasion } \\
\hline Negative & 33 & 7 & 26 & \\
\hline Positive & 11 & 7 & 4 & 0.014 \\
\hline \multicolumn{5}{|c|}{ Pancreatic cut end margin } \\
\hline Negative & 40 & 11 & 29 & \\
\hline Positive & 4 & 3 & 1 & 0.088 \\
\hline
\end{tabular}

A significant correlation between STAT5b expression in cancer cells and main pancreatic duct invasion was observed. UICC, International Union Against Cancer; Ns, not significant.

cells on the upper surface of the filter were carefully removed with a cotton swab and membranes were fixed in methanol and stained with crystal violet. The cells that had migrated through the membrane to the lower surface of the filter were counted using a microscope. Each assay was performed in duplicate and experiments were repeated three times.

Patients and tissue samples. Tissues from 44 patients with invasive PDAC were obtained for the present study. The patients received treatment at Nippon Medical School Hospital (Tokyo, Japan) from 2009 to 2013. All patients underwent either a pancreatoduodenectomy or a distal pancreatectomy, and received adjuvant or neoadjuvant chemotherapy with gemcitabine alone or gemcitabine combination regimen. Patients were 27 males and 17 females, and median age was 69 years (range, 37-88 years). Clinicopathological stage was determined according to the TNM classification system of the International Union Against Cancer (UICC) and additionally characterized according to the Japan Pancreas Society classification (Table I). The median follow-up period was 21 months. Paraffin-embedded samples were prepared for immunohistochemical analysis as previously described (28). This study was carried out in accordance with the principles embodied in the Declaration of Helsinki, 2008, and informed consent for the use of pancreatic tissues was obtained from each patient.

Immunohistochemistry. Paraffin-embedded sections (3 $\mu \mathrm{m})$ were immunostained using a Histofine Simple Stain MAX PO (R) or (M) kit. After deparaffinization, the tissue sections were preheated in $10 \mathrm{mM}$ citrate buffer solution ( $\mathrm{pH} \mathrm{6.0)}$ for $5 \mathrm{~min}$ at $121^{\circ} \mathrm{C}$. Then, endogenous peroxidase activity was blocked by incubation for $30 \mathrm{~min}$ with $0.3 \%$ hydrogen peroxide in methanol. The tissue sections were then incubated with the anti-STAT5b antibody (1:50 in dilution) in phosphate-buffered saline (PBS) containing $1 \%$ bovine serum albumin (BSA) overnight at $4^{\circ} \mathrm{C}$. Bound antibodies were detected with the Simple Stain MAX PO (R) or (M) reagent, using diaminobenzidine tetrahydrochloride as the substrate. The sections were then counterstained with Mayer's hematoxylin. Negative control tissue sections were prepared by omitting the primary antibody. As for the evaluation of immunostaining, both intensity and proportion of positively stained cancer cells were analyzed at magnification $\mathrm{x} 200$.

Statistical analysis. Student's t-test was used for statistical analysis of the cell proliferation assay, sensitivity of antineoplastic agents assay, adhesion assay, invasion assay and densitometry analysis. $\chi^{2}$ test and Fisher's exact test were used to analyze the correlation between STAT5b expression and clinicopathological characteristics. Cumulative survival rates were calculated by the Kaplan-Meier method. Significant difference was set at $\mathrm{P}<0.05$. All statistical tests were determined using the Software Package SPSS for Windows (version 12.0; SPSS, Inc., Chicago, IL, USA).

\section{Results}

Expression of STAT5b $\mathrm{mRNA}$ and protein in pancreatic cancer cells. We performed qRT-PCR analysis to investigate the relative expression levels of STAT5b mRNA in pancreatic 

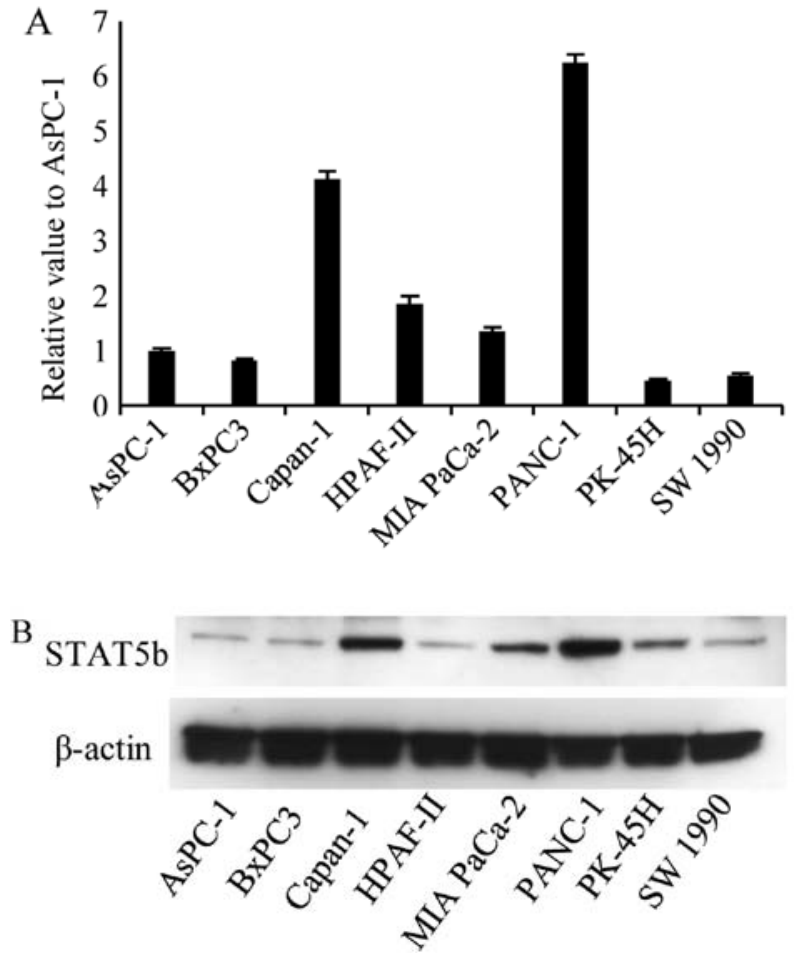

Figure 1. Expression of STAT5b mRNA and protein in pancreatic cancer cells. (A) Quantitative RT-PCR analysis of STAT5b mRNA levels. STAT5b mRNA expressed in all pancreatic cancer cell lines, and the levels were highest in PANC-1 cells, second highest in Capan-1 cells, and lowest in PK-45H cells. In PANC-1 cells, STAT5b mRNA levels were $\sim 13.5$-fold higher than in PK-45H cells. (B) Western blot analysis of STAT5b protein levels. STAT5b protein was detected in all cell lines consistent with the RT-PCR results and the levels were highest in PANC-1 cells and second highest in Capan-1 cells.

cancer cell lines, including AsPC-1, BxPC3, Capan-1, HPAF-2 MIA PaCa-2, PANC-1, PK-45H and SW1990. STAT5b mRNA was detected in all pancreatic cancer cell lines, and the relative levels were highest in PANC-1 cells, second highest in Capan-1 cells and lowest in PK-45H cells. In PANC-1 cells, STAT5b mRNA levels were 13.5-fold higher than in PK-45H cells (Fig. 1A). Western blot analysis was also performed to examine the STAT5b protein levels with the same eight pancreatic cancer cell lines. Consistent with our qRT-PCR results, STAT5b protein was detected in all cell lines, with the highest protein levels in PANC-1 cells and second highest levels in Capan-1 cells (Fig. 1B).

Localization and activation of STAT5b in pancreatic cancer cells. Confocal immunofluorescence microscopy analysis was next carried out to determine the subcellular localization of STAT5b in PANC-1 and MIA PaCa-2 cells. This analysis revealed that STAT5b was distributed in the nuclei and cytoplasm in both cell types (Fig. 2A). Similarly, western blotting using nuclear and cytoplasmic fractions detected STAT5b protein in both the nuclei and the cytoplasm (Fig. 2B). To investigate the activation of STAT5b in the two cell types, the cell lysates were immunoprecipitated with anti-STAT5b antibody followed by western blotting with anti-phosphotyrosine or anti-STAT5b antibodies. This analysis revealed the phosphorylation of STAT5b in the same two pancreatic cancer cell types (Fig. 2C).
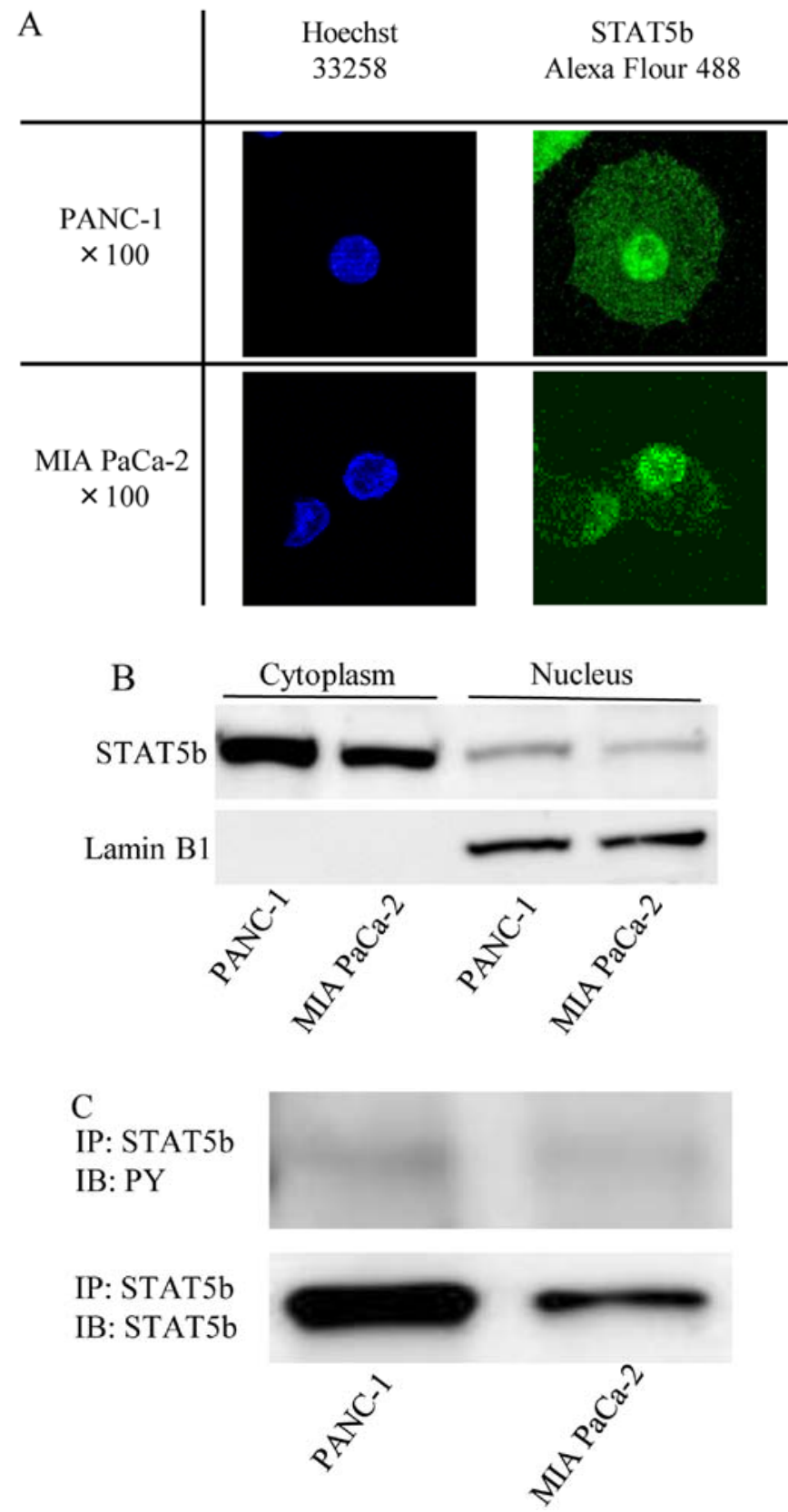

Figure 2. Localization and activation of STAT5b in PANC-1 and MIA PaCa-2 pancreatic cancer cells. (A) Confocal microscopy analysis. Both PANC-1 and MIA PaCa-2 cells were subjected to immunofluorescent staining for STAT5b (green, Alexa Fluor 488). Nuclei were stained with Hoechst 33258 dye (blue). STAT5b was distributed in the nuclei and cytoplasm (representative sections, original magnification, x100). (B) Western blotting after cell fractionation. PANC-1 and MIA PaCa-2 cells were fractionated into nuclear and cytoplasmic fractions and subjected to western blotting. Antibodies were directed against STAT5b and lamin B1 to validate fraction purity and protein loading. In agreement with the results of confocal microscopy analysis, STAT5b protein was detected in both nuclei and cytoplasm. (C) Immunoprecipitation and western blotting. The cell lysates were immunoprecipitated (IP) with antiSTAT5b antibody followed by western blotting with anti-phosphotyrosine (PY) or anti-STAT5b antibodies. This analysis demonstrated the phosphorylation of STAT5b in the same two pancreatic cancer cell types.

Effects of STAT5b shRNA on STAT5b levels on the growth of PANC-1 cells. PANC-1 cells are ideal for assessing the role of endogenous STAT5b in pancreatic cancer cells because they express relatively high levels of STAT5b protein. Therefore, PANC-1 cells were stably transfected with a plasmid vector 
A
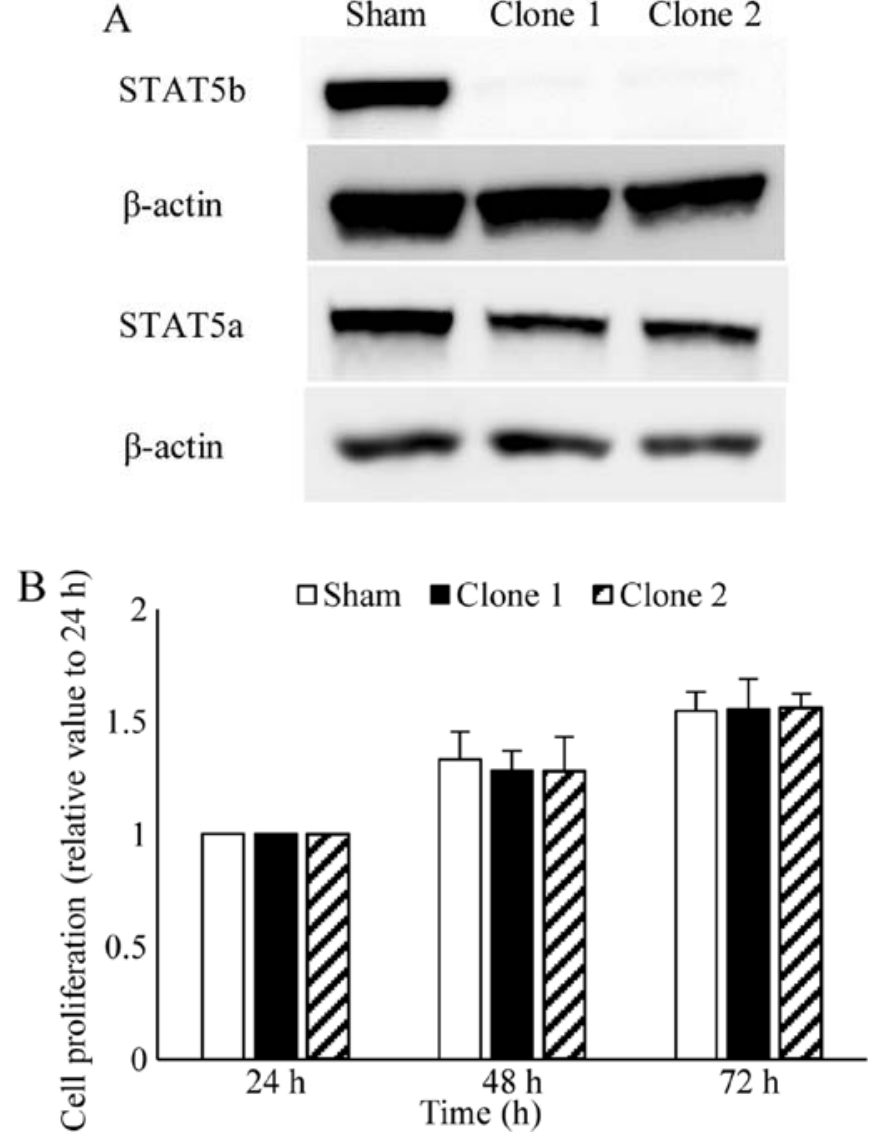

Figure 3. Effects of STAT5b shRNA on STAT5b levels on the growth of PANC-1 cells. (A) Western blot analysis of STAT5b and STAT5a protein levels after stable transfection. PANC-1 cells, which expressed relatively high levels of STAT5b mRNA and protein, were stably transfected with a plasmid vector encoding shRNAs targeting the STAT5b transcripts. Two kinds of clones transfected with the STAT5b shRNAs exhibited the inhibition of STAT5b and uninhibited STAT5a (the isoform of STAT5) expression after transfection. (B) Cell proliferation assay after the stable transfection. Sham and two kinds of STAT5b shRNA expressing clones were seeded in a 96-well plate at a density of $8.0 \times 10^{3}$ cells/well and incubated at $37^{\circ} \mathrm{C}$ for 24 , 48 or $72 \mathrm{~h}$. After the indicated time, there was no significant difference at all in cell proliferation capability between sham and both STAT5b shRNA expressing clones.

encoding shRNAs targeting the STAT5b transcripts. Clones transfected with the STAT5b shRNAs showed inhibition of STAT5b, and uninhibited STAT5a protein expression by western blotting (Fig. 3A). To assess the consequence of reduced STAT5b expression on proliferation ability, cell growth was investigated by cell proliferation assay. There was no significant difference between the sham-transfected cells and the STAT5b shRNA clones (Fig. 3B).

Effects of STAT5b suppression on gemcitabine-treated actions. The chemotherapeutic agent gemcitabine has been the standard treatment in patients with PDAC for more than a decade since Burris et al (4). We therefore, compared the effects of gemcitabine on growth and apoptosis in sham-transfected and STAT5b shRNA clones by cell proliferation assay as described above to investigate the effect of gemcitabine treatment on proliferation ability with STAT5b suppression. Treatment with gemcitabine for 48 or $72 \mathrm{~h}$ resulted in a dose-dependent reduction in cell growth. In the sham-transfected cells, a maximum
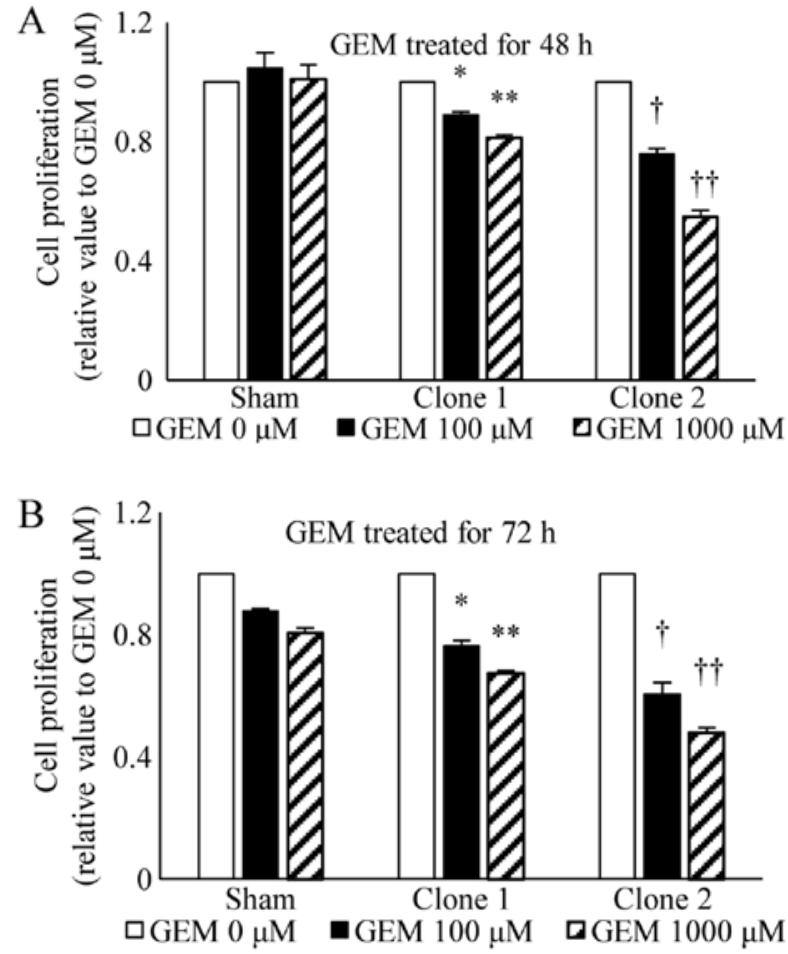

Figure 4. Effects of STAT5b suppression on gemcitabine-treated actions Sham and STAT5b shRNA clones, seeded in the same way as the cell proliferation assay, were treated with absence or presence of 100 or $1,000 \mu \mathrm{M}$ gemcitabine for 48 or $72 \mathrm{~h}$ (A and B). Treatment with gemcitabine resulted in a dose-dependent reduction in cell growth. In the sham-transfected cells, a maximum decrease of $19.4 \%$ occurred at a concentration of $1,000 \mu \mathrm{M}$ gemcitabine and 72-h incubation. By contrast, both STAT5b shRNA clones exhibited a significantly greater growth inhibitory effect of $32.6 \%(\mathrm{P}<0.01)$ and $52 \%(\mathrm{P}<0.001)$, respectively with the same concentration of gemcitabine and incubation time. (A) ${ }^{*} \mathrm{P}<0.05,{ }^{* *} \mathrm{P}<0.02,{ }^{\dagger} \mathrm{P}<0.01$ and ${ }^{\dagger \dagger} \mathrm{P}<0.001$. (B) ${ }^{*} \mathrm{P}<0.02,{ }^{* *} \mathrm{P}<0.01,{ }^{\dagger} \mathrm{P}<0.01$ and ${ }^{\dagger \dagger} \mathrm{P}<0.001$

decrease of $19.4 \%$ occurred at a concentration of $1,000 \mu \mathrm{M}$ gemcitabine and 72-h incubation. By contrast, both STAT5b shRNA clones exhibited a significantly greater growth inhibitory effect of 32.6 and $52 \%$, respectively with the same concentration of gemcitabine and incubation time (Fig. 4).

Effects of endogenous STAT5b levels on gemcitabine-treated actions in pancreatic cancer cells. We next investigated the effects of gemcitabine on growth in PANC-1, AsPC-1 and BxPC cells by cell proliferation assay as described above, in order to compare the effect of gemcitabine treatment on proliferation of pancreatic cancer cells which express high and low levels of STAT5b. Treatment with gemcitabine for $72 \mathrm{~h}$ resulted in a dose-dependent reduction in cell growth. In PANC-1 cells which expressed relatively high levels of STAT5b, a maximum decrease of $22.1 \%$ occurred at a concentration of $1,000 \mu \mathrm{M}$ gemcitabine and 72-h incubation. Both AsPC-1 and BxPC3 cells, which express relatively low levels of STAT5b, exhibited a significant decrease in growth by treatment with gemcitabine compared to PANC-1 cells for $72 \mathrm{~h}$ (Fig. 5).

Effects of overexpressed STAT5b levels on the growth of AsPC-1 cells and on gemcitabine-treated actions. AsPC-1 cells, which express relatively low levels of STAT5b protein, were stably transfected with a plasmid vector encoding STAT5b 


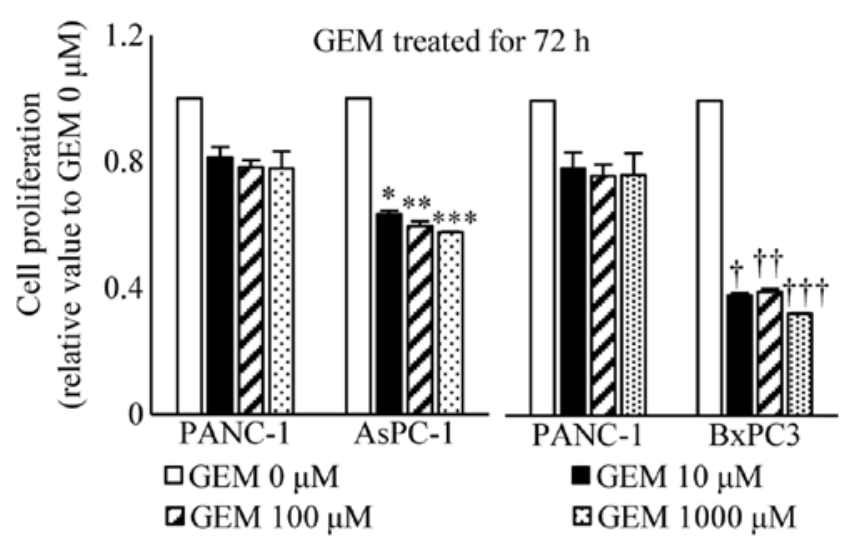

Figure 5. Treatment with gemcitabine for $72 \mathrm{~h}$ resulted in a dose-dependent decrease in cell growth. In the PANC-1 cells which expressed relatively high levels of STAT5b, a maximum decrease occurred at a concentration of 1,000 $\mu \mathrm{M}$ gemcitabine and 72-h incubation. Compared to PANC-1 cells, both AsPC-1 and BxPC3 cells which express relatively low levels of STAT5b, exhibited significantly decreased growth by treatment with gemcitabine for 72 h. ${ }^{*} \mathrm{P}<0.01,{ }^{* *} \mathrm{P}<0.01,{ }^{* * *} \mathrm{P}<0.01,{ }^{+} \mathrm{P}<0.002,{ }^{\dagger+} \mathrm{P}<0.001$ and ${ }^{\dagger \dagger} \mathrm{P}<0.01$.

full-length cDNA, in order to investigate and compare the role of STAT5b in pancreatic cancer cells. Clones transfected with the STAT5b cDNA exhibited overexpression of STAT5b, verified by western blotting (Fig. 6A). To assess the effect of overexpressed STAT5b expression on proliferation ability, cell growth was measured by cell proliferation assay. No significant difference between the sham-transfected cells and the STAT5b overexpressing clones was observed (Fig. 6B). We performed cell proliferation assay with gemcitabine treatment, as described above, to determine the effect of gemcitabine treatment on proliferation ability with STAT5b overexpression clones. Treatment with gemcitabine for $72 \mathrm{~h}$ resulted in a significant increase in growth of overexpressed clones compared to sham-transfected cells (Fig. 6C).

Effects of gemcitabine on pro-apoptotic actions and apoptosis-regulating protein Bcl-xL. The deregulation of apoptosis (29) is an indicator of carcinogenesis and the induction of apoptosis is a standard strategy for anticancer therapies (30). Therefore, we examined the expression of known apoptosis-related proteins, cleaved caspase- 3 and PARP (31), by western blotting to investigate whether gemcitabine treatment for STAT5b shRNA clones induced greater apoptotic actions than the sham-transfected cells. After treatment with gemcitabine for $72 \mathrm{~h}$, both STAT5b shRNA clones exhibited a stronger expression of cleaved caspase-3 and PARP than the sham-transfected cells (Fig. 7A). STAT5 is known to upregulate Bcl-xL expression and STAT5 has been implicated in the regulation of apoptosis (32). Therefore, we next sought to determine whether the levels of these transcription factors were altered in our cells. Gemcitabine markedly reduced Bcl-xL levels in the STAT5b shRNA cells compared with the sham-transfected cells (Fig. 7B). Relative values of PARP and Bcl-xL proteins were calculated by quantitative densitometry. Band densities of PARP protein significantly increased in STAT5b shRNA clones compared to shamtransfected cells (Fig. 7C). Band densities of Bcl-xL protein significantly decreased in STAT5b shRNA clones compared to sham-transfected cells (Fig. 7D).
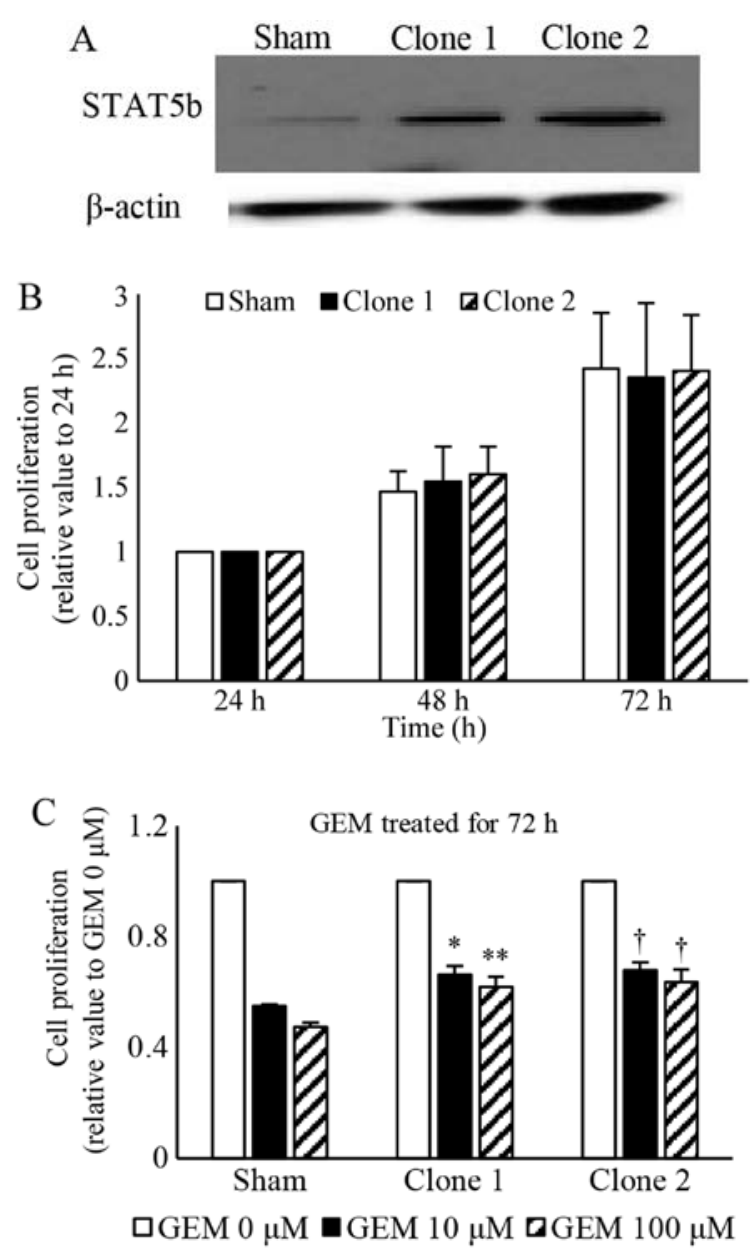

Figure 6. Effects of overexpressed STAT5b levels on the growth of AsPC-1 cells and on gemcitabine-treated actions. (A) Western blot analysis of STAT5b protein levels after stable transfection. AsPC-1 cells, which express relatively low levels of STAT5b protein, were stably transfected with a plasmid vector encoding STAT5b full-length cDNA. Clones transfected with the STAT5b cDNA exhibited overexpression of STAT5b by western blotting. (B) Cell proliferation assay after the stable transfection. Sham and two kinds of STAT5b overexpressing clones were seeded in a 96-well plate at a density of $8.0 \times 10^{3}$ cells/well and incubated at $37^{\circ} \mathrm{C}$ for 24,48 and $72 \mathrm{~h}$. After the specified time, no significant difference in cell proliferation capability was observed between sham and the STAT5b overexpressing clones. (C) Cell proliferation assay with gemcitabine treatment after the stable transfection. Treatment with gemcitabine for $72 \mathrm{~h}$ resulted in a significant increase in growth of overexpressed clones compared to sham. ${ }^{*} \mathrm{P}<0.03,{ }^{* *} \mathrm{P}<0.02$ and ${ }^{\dagger} \mathrm{P}<0.03$.

Effects of reduced STAT5b levels in PANC-1 cells on adhesion and invasion. Cancer cell adhesion is a process that involves cancer cells interacting with adjacent cancer cells as well as with extracellular matrix components (33). For tumors to metastasize and grow, neoplastic and endothelial cells must invade into surrounding tissues. The ability to block the invasive capacity of tumor cells therefore offers a new approach to treating patients with malignant disease (34). Hence, we next compared the effects of STAT5b suppression on cell adhesion and invasion. In comparison to sham-transfected cells, the adhesion assay for both STAT5b shRNA clones exhibited a significantly reduced adhesion to fibronectin $(\mathrm{P}<0.001)$, laminin $(\mathrm{P}<0.001)$, and collagen IV $(\mathrm{P}<0.002)$, which are known as major types of extracellular matrices (ECM) (Fig. 8A). Similarly, compared to sham-transfected cells, 


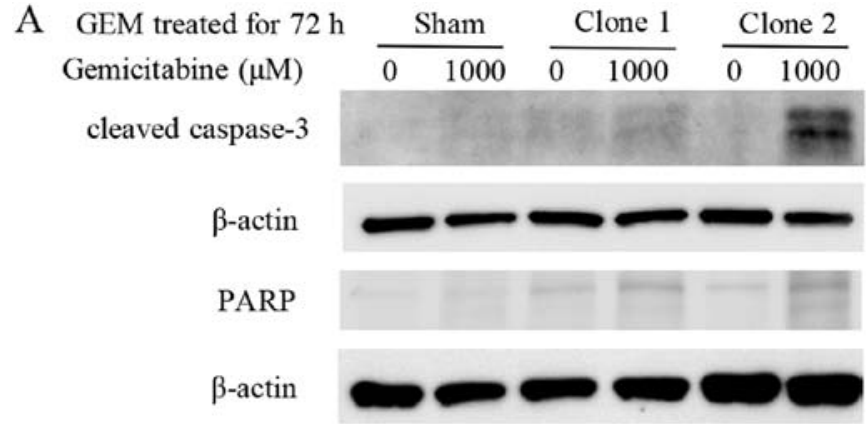

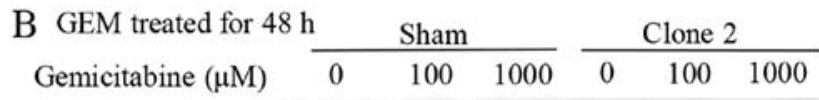
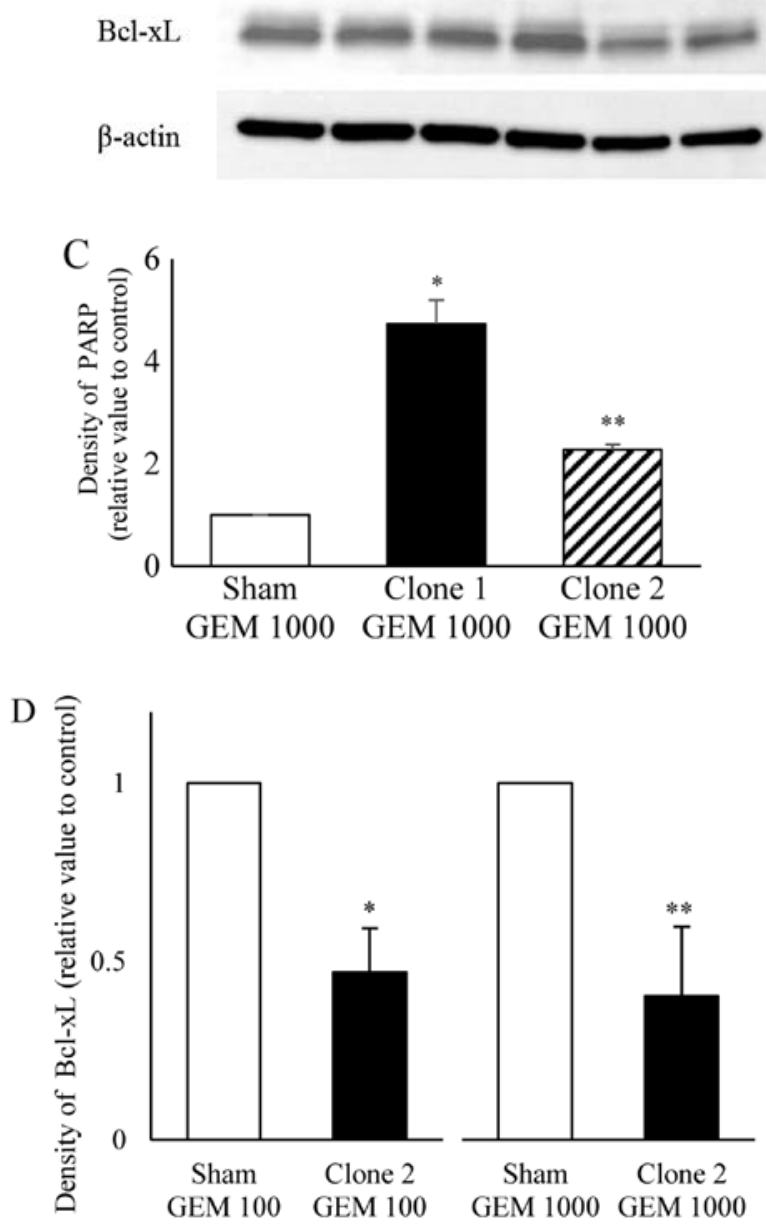

Figure 7. Effects of gemcitabine on pro-apoptotic actions and apoptosisregulating proteins, Bcl-xL. (A) Western blot analysis of cleaved caspase-3 and PARP (known as apoptosis-related proteins). Both STAT5b shRNA clones exhibited a stronger expression of cleaved caspase-3 and PARP than the sham-transfected cells after treatment with gemcitabine for $72 \mathrm{~h}$. (B) Western blot analysis of Bcl-xL. Gemcitabine markedly reduced Bcl-xL protein levels in STAT5b shRNA cells after treatment with gemcitabine for $48 \mathrm{~h}$, compared to sham-transfected cells. (C and D) Densitometry of PARP and Bcl-xL proteins. The band densities of PARP protein (C) significantly increased in STAT5b shRNA clones compared to sham-transfected cells $\left({ }^{*} \mathrm{P}<0.002\right.$ and $\left.^{* *} \mathrm{P}<0.001\right)$. The band densities of $\mathrm{Bcl}-\mathrm{xL}$ protein (D) significantly decreased in STAT5b shRNA clone compared to sham-transfected cells ( ${ }^{*} \mathrm{P}<0.02$ and $\left.{ }^{* *} \mathrm{P}<0.04\right)$.

both clones exhibited significantly reduced ability to invade across a Matrigel membrane treated with FBS $(\mathrm{P}<0.02)$, EGF $(\mathrm{P}<0.01)$ and $\mathrm{PDGF}(\mathrm{P}<0.02)$ in the invasion assay (Fig. 8B).
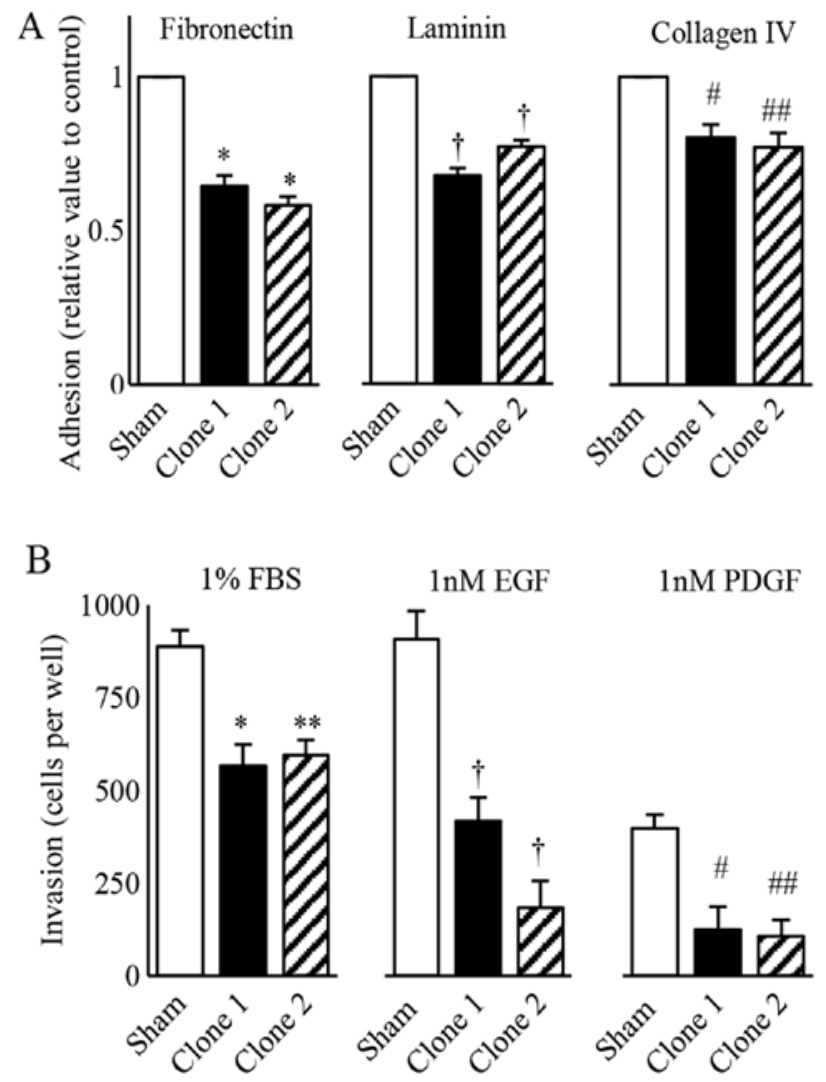

Figure 8. Effects of reduced STAT5b levels in PANC-1 cells on adhesion and invasion. (A) Adhesion assay with sham-transfected and STAT5b shRNA expressing clones. In comparison with sham-transfected cells, both STAT5b shRNA expressing clones exhibited a significantly reduced adhesion to fibronectin, laminin and collagen IV, which are known as major types of extracellular matrices. ${ }^{*} \mathrm{P}<0.001,{ }^{ } \mathrm{P}<0.001, \# \mathrm{P}<0.02$ and ${ }^{\# \#} \mathrm{P}<0.01$. (B) Invasion assay with sham-transfected and STAT5b shRNA expressing clones. In comparison with sham-transfected cells, both STAT5b shRNA clones exhibited significantly reduced ability to invade across a Matrigel membrane treated with FBS, EGF and PDGF. ${ }^{*} \mathrm{P}<0.02,{ }^{* *} \mathrm{P}<0.01,{ }^{\dagger} \mathrm{P}<0.01$, ${ }^{\#} \mathrm{P}<0.02$ and ${ }^{\# \#} \mathrm{P}<0.01$.

Cumulative Kaplan-Meier survival curve and correlation of clinicopathological characteristics with STAT5b expression. Immunohistochemical results for STAT5b were evaluated as the expression index; 'staining percentage of the tumor cell' multiplied by 'staining intensity (0-2)'. We set $0-20$ index as weak (29 cases) (Fig. 9A), and 30-120 index as strong (15 cases) (Fig. 9B). However, there was a trend toward reduced overall survival of patients in the STAT5b-strong group, but a significant difference in the overall survival rate between the STAT5b-weak group and STAT5b-strong group was not observed ( $\mathrm{P}=0.35)$ (Fig. 9C). Clinicopathologically, a significant correlation between STAT5b expression in the cancer cells and main pancreatic duct invasion $(\mathrm{P}=0.014)$. (Table I) was observed.

\section{Discussion}

In the present study, we demonstrated expression of STAT5b in human pancreatic cancer cells by RT-PCR (Fig. 1A) and western blot analysis (Fig. 2A). STAT5b is activated by cytokines and some growth factors. Phosphorylation of STAT5b by tyrosine kinases is so far the best-documented mechanism 

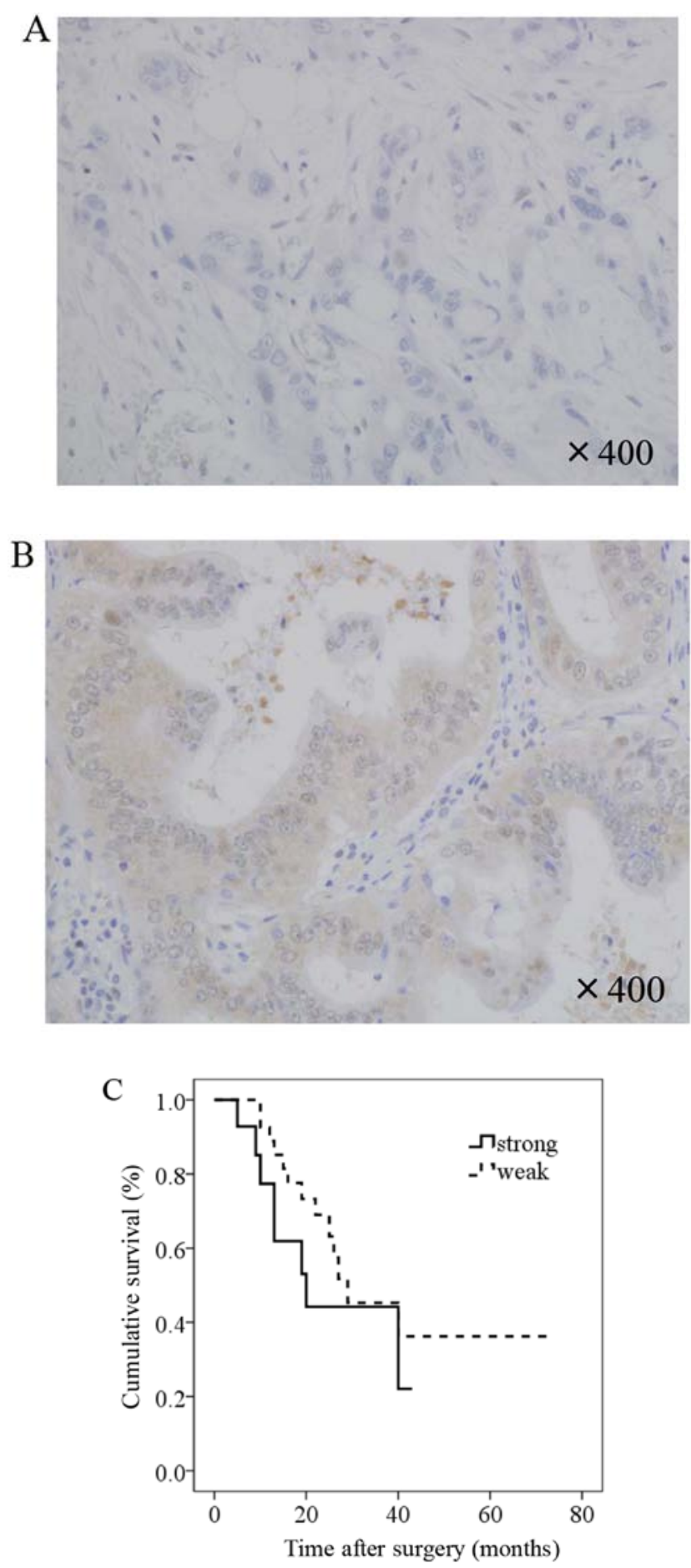

Figure 9. Cumulative Kaplan-Meier survival curve and correlation of clinicopathological characteristics with STAT5b expression. Immunohistochemical results for STAT5b were evaluated as the expression index; 'staining percentage of the tumor cells' multiplied by 'staining intensity (0-2)'. (A) We set 0-20 index as weak (29 cases, original magnification, $x 400$ ), and (B) 30-120 index as strong (15 cases, original magnification, $x 400)$. (C) Cumulative Kaplan-Meier survival curve. A significant difference $(\mathrm{P}=0.35)$ was not observed in the overall survival rates of the STAT5b-weak group and STAT5b-strong group.

of STAT5b activation. We also showed that STAT5b is localized in both the cytoplasm and nuclei by confocal microscopy (Fig. 2A) and by western blot analysis using cell fractionation (Fig. 2B). Immunoprecipitation analysis further revealed tyrosine phosphorylation of STAT5b (Fig. 2C). These results indicate that STAT5b in pancreatic cancer cells is constitutively activated.

STAT5b are frequently expressed in the nuclei of tumor cells in borderline intraductal papillary mucinous neoplasms (IPMNs) and intraductal papillary mucinous carcinomas but not in intraductal papillary mucinous adenomas (23). Since the nuclear expression of STAT5b protein correlated to the Ki-67 labeling index of the IPMNs, STAT5b protein can contribute to the progression and proliferation of IPMNs (23). On the contrary, we could not detect significant proliferation differences between sham and STAT5b-shRNA clones in pancreatic cancer cells in the present study. In PDAC, STAT5b protein may not contribute to proliferation.

Substantial evidence suggests that STAT5 is associated with chemoresistance and apoptosis in PDAC. First, curcubitacin B, an experimental drug for pancreatic cancer, causes dose- and time-dependent G(2)-M-phase arrest and apoptosis of pancreatic cancer cells in association with inhibition of activated STAT5, STAT3 and JAK2 (35). Second, downregulation in pancreatic cancer cells of neuropilin-1, a coreceptor for vascular endothelial growth factor-A (VEGF-A), is associated with increased sensitivity to an antineoplastic agent, with proapoptotic actions, and with reduced STAT5 and Bcl-xL protein levels (26). Third, Bcl-xL plays a vital role in pancreatic cancer chemoresistance; the increased expression of this antiapoptotic protein is associated with poor survival $(36,37)$. Fourth, STAT5 has a crucial role in antiapoptotic signaling of the erythropoietin receptor and mediates the immediate-early induction of Bcl-xL (32). In the present study, although there was no significant difference of proliferation between the sham and STAT5b shRNA clones without gemcitabine treatment (Fig. 3B), as for gemcitabine resistance, PANC-1 STAT5b shRNA clones with gemcitabine treatment exhibited a significantly greater growth inhibitory effect compared to sham-transfected cells (Fig. 4). Compared with PANC-1 cells which expressed relatively high levels of STAT5b, both AsPC-1 and BxPC3 cells which express relatively low levels of STAT5b exhibited significantly decreased growth by treatment with gemcitabine (Fig. 5). Moreover, treatment with gemcitabine resulted in significant increase in the growth of AsPC-1 STAT5b overexpression clones compared to sham-transfected cells (Fig. 6B). These results suggest that STAT5b in pancreatic cancer cells play an important role in gemcitabine chemoresistance.

In this study, a significant clinicopathological correlation between STAT5b expression and overall survival rates of PDAC was observed (Fig. 9C). However, even with the limited number of patients, a tendency toward reduced overall survival for patients receiving neoadjuvant or adjuvant gemcitabine treatments in the STAT5b-strong group. These results suggest a correlation between STAT5b expression/activation and clinical gemcitabine resistance. In our immunohistochemical study, a correlation between expression of STAT5b in PDAC and main pancreatic duct invasion was observed (Table I). This suggests that STAT5b may also play an important role in the invasiveness of PDAC.

Regarding apoptosis, the caspase-3 activity was upregulated in gemcitabine-treated STAT5b-shRNA clones with subsequent cleavage of PARP protein (Fig. 7A). This activation was associated with increased levels of apoptosis in the pancreatic cancer cells. Gemcitabine also decreased Bcl-xL 
levels in the STAT5b-shRNA expressing cells, but not in the sham-transfected cells (Fig. 7B). These observations suggest that STAT5 may contribute to the antiapoptotic effects of pancreatic cancer cells by inducing Bcl-xL.

EGF is capable of activating STAT5b, signaling of which is mediated by the EGF receptor (38). PDGF is also capable of activating STAT5, mediated by the PDGF $\beta$-receptor (39). Both EGF and PDGF-induced activation of STAT5 are independent of JAK family kinases and both EGF receptor and PDGF $\beta$-receptor have been shown to activate STAT5 $(38,39)$. Thus, several tyrosine kinase receptors have the ability to directly activate STAT5. In the present study, downregulation of STAT5b resulted in reduced adhesion and invasion of pancreatic cancer cells in vitro (Fig. 8). Notably, EGF- and PDGF-induced invasion were inhibited by downregulation of STAT5b. These results may indicate that STAT5b has a pivotal role in both EGF and PDGF signaling pathways in PDAC.

Taken together, our results suggest that targeting STAT5b in PDAC may enhance the effectiveness of other therapeutic modalities by enhancing gemcitabine chemosensitivity, increasing apoptosis and suppressing cellular adhesion and invasion.

\section{Acknowledgements}

The authors would like to thank Mrs. Sumie Etoh of Nippon Medical School for her excellent technical assistance. The present study was supported by a Grant-in-Aid for Scientific Research (C) from the Japan Society for the Promotion of Science (No. 26462075 to A.M.).

\section{References}

1. Siegel R, Ma J, Zou Z and Jemal A: Cancer statistics, 2014. CA Cancer J Clin 64: 9-29, 2014.

2. Hidalgo M: Pancreatic cancer. N Engl J Med 362: 1605-1617, 2010 .

3. Stathis A and Moore MJ: Advanced pancreatic carcinoma: Current treatment and future challenges. Nat Rev Clin Oncol 7: $163-172,2010$

4. Burris HA III, Moore MJ, Andersen J, Green MR, Rothenberg ML, Modiano MR, Cripps MC, Portenoy RK, Storniolo AM, Tarassoff $\mathrm{P}$, et al: Improvements in survival and clinical benefit with gemcitabine as first-line therapy for patients with advanced pancreas cancer: A randomized trial. J Clin Oncol 15: 2403-2413, 1997.

5. Mini E, Nobili S, Caciagli B, Landini I and Mazzei T: Cellular pharmacology of gemcitabine. Ann Oncol 17 (Suppl 5): v7-v12, 2006.

6. Bowman T, Garcia R, Turkson J and Jove R: STATs in oncogenesis. Oncogene 19: 2474-2488, 2000.

7. Yu H and Jove R: The STATs of cancer - new molecular targets come of age. Nat Rev Cancer 4: 97-105, 2004.

8. Darnell JE Jr: STATs and gene regulation. Science 277: $1630-1635,1997$.

9. Ferbeyre G and Moriggl R: The role of Stat5 transcription factors as tumor suppressors or oncogenes. Biochim Biophys Acta 1815: 104-114, 2011

10. Levine RL, Pardanani A, Tefferi A and Gilliland DG: Role of JAK2 in the pathogenesis and therapy of myeloproliferative disorders. Nat Rev Cancer 7: 673-683, 2007.

11. Scholz A, Heinze S, Detjen KM, Peters M, Welzel M, Hauff P, Schirner M, Wiedenmann B and Rosewicz S: Activated signal transducer and activator of transcription 3 (STAT3) supports the malignant phenotype of human pancreatic cancer. Gastroenterology 125: 891-905, 2003.

12. Sahu RP and Srivastava SK: The role of STAT-3 in the induction of apoptosis in pancreatic cancer cells by benzyl isothiocyanate. J Natl Cancer Inst 101: 176-193, 2009.
13. Wakao H, Gouilleux F and Groner B: Mammary gland factor (MGF) is a novel member of the cytokine regulated transcription factor gene family and confers the prolactin response. EMBO J 13: 2182-2191, 1994.

14. Ren S, Cai HR, Li M and Furth PA: Loss of Stat5a delays mammary cancer progression in a mouse model. Oncogene 21: 4335-4339, 2002.

15. Vafaizadeh V, Klemmt P, Brendel C, Weber K, Doebele C, Britt K, Grez M, Fehse B, Desriviéres S and Groner B: Mammary epithelial reconstitution with gene-modified stem cells assigns roles to Stat5 in luminal alveolar cell fate decisions, differentiation, involution, and mammary tumor formation. Stem Cells 28: 928-938, 2010.

16. Ahonen TJ, Xie J, LeBaron MJ, Zhu J, Nurmi M, Alanen K, Rui $\mathrm{H}$ and Nevalainen MT: Inhibition of transcription factor Stat5 induces cell death of human prostate cancer cells. J Biol Chem 278: 27287-27292, 2003.

17. Kazansky AV, Spencer DM and Greenberg NM: Activation of signal transducer and activator of transcription 5 is required for progression of autochthonous prostate cancer: Evidence from the transgenic adenocarcinoma of the mouse prostate system. Cancer Res 63: 8757-8762, 2003.

18. Lee TK, Man K, Poon RT, Lo CM, Yuen AP, Ng IO, Ng KT, Leonard W and Fan ST: Signal transducers and activators of transcription $5 \mathrm{~b}$ activation enhances hepatocellular carcinoma aggressiveness through induction of epithelial-mesenchymal transition. Cancer Res 66: 9948-9956, 2006.

19. Pastuszak-Lewandoska D, Domańska D, Czarnecka KH, Kordiak J, Migdalska-Sęk M, Nawrot E, Kiszałkiewicz J, Antczak A, Górski P and Brzeziańska E: Expression of STAT5, COX-2 and PIAS3 in correlation with NSCLC histhopathological features. PLoS One 9: e104265, 2014.

20. Du W, Wang YC, Hong J, Su WY, Lin YW, Lu R, Xiong H and Fang JY: STAT5 isoforms regulate colorectal cancer cell apoptosis via reduction of mitochondrial membrane potential and generation of reactive oxygen species. J Cell Physiol 227: 2421-2429, 2012

21. Liang QC, Xiong H, Zhao ZW, Jia D, Li WX, Qin HZ, Deng JP, Gao L, Zhang H and Gao GD: Inhibition of transcription factor STAT5b suppresses proliferation, induces G1 cell cycle arrest and reduces tumor cell invasion in human glioblastoma multiforme cells. Cancer Lett 273: 164-171, 2009.

22. Jackerott M, Møldrup A, Thams P, Galsgaard ED, Knudsen J, Lee YC and Nielsen JH: STAT5 activity in pancreatic beta-cells influences the severity of diabetes in animal models of type 1 and 2 diabetes. Diabetes 55: 2705-2712, 2006.

23. Kataoka TR, Ioka T, Tsukamoto Y, Matsumura M, Ishiguro S and Nishizawa Y: Nuclear expression of STAT5 in intraductal papillary mucinous neoplasms of the pancreas. Int J Surg Pathol 15: 277-281, 2007.

24. Canales NA, Marina VM, Castro JS, Jiménez AA, Mendoza-Hernández G, McCARRON EL, Roman MB and Castro-Romero JI: A1BG and C3 are overexpressed in patients with cervical intraepithelial neoplasia III. Oncol Lett 8: 939-947, 2014.

25. Matsushita A, Götze T and Korc M: Hepatocyte growth factormediated cell invasion in pancreatic cancer cells is dependent on neuropilin-1. Cancer Res 67: 10309-10316, 2007.

26. Fukasawa M, Matsushita A and Korc M: Neuropilin-1 interacts with integrin betal and modulates pancreatic cancer cell growth, survival and invasion. Cancer Biol Ther 6: 1173-1180, 2007.

27. Rowland-Goldsmith MA, Maruyama H, Kusama T, Ralli S and Korc M: Soluble type II transforming growth factor-beta (TGF-beta) receptor inhibits TGF-beta signaling in COLO-357 pancreatic cancer cells in vitro and attenuates tumor formation. Clin Cancer Res 7: 2931-2940, 2001.

28. Kawamoto M, Ishiwata T, Cho K, Uchida E, Korc M, Naito Z and Tajiri T: Nestin expression correlates with nerve and retroperitoneal tissue invasion in pancreatic cancer. Hum Pathol 40: 189-198, 2009.

29. Kang N, Zhang JH, Qiu F, Tashiro S, Onodera S and Ikejima T: Inhibition of EGFR signaling augments oridonin-induced apoptosis in human laryngeal cancer cells via enhancing oxidative stress coincident with activation of both the intrinsic and extrinsic apoptotic pathways. Cancer Lett 294: 147-158, 2010 . 
30. Strasser A, Cory S and Adams JM: Deciphering the rules of programmed cell death to improve therapy of cancer and other diseases. EMBO J 30: 3667-3683, 2011.

31. Schimmer AD, Hedley DW, Penn LZ and Minden MD: Receptorand mitochondrial-mediated apoptosis in acute leukemia: A translational view. Blood 98: 3541-3553, 2001.

32. Socolovsky M, Fallon AE, Wang S, Brugnara C and Lodish HF: Fetal anemia and apoptosis of red cell progenitors in Stat5a/-5b-/- mice: A direct role for Stat5 in Bcl-X(L) induction. Cell 98: 181-191, 1999.

33. Liotta LA, Steeg PS and Stetler-Stevenson WG: Cancer metastasis and angiogenesis: An imbalance of positive and negative regulation. Cell 64: 327-336, 1991.

34. Hood JD and Cheresh DA: Role of integrins in cell invasion and migration. Nat Rev Cancer 2: 91-100, 2002.

35. Thoennissen NH, Iwanski GB, Doan NB, Okamoto R, Lin P, Abbassi S, Song JH, Yin D, Toh M, Xie WD, et al: Cucurbitacin $\mathrm{B}$ induces apoptosis by inhibition of the JAK/STAT pathway and potentiates antiproliferative effects of gemcitabine on pancreatic cancer cells. Cancer Res 69: 5876-5884, 2009.
36. Ghaneh P, Kawesha A, Evans JD and Neoptolemos JP: Molecular prognostic markers in pancreatic cancer. J Hepatobiliary Pancreat Surg 9: 1-11, 2002.

37. Takahashi H, Chen MC, Pham H, Matsuo Y, Ishiguro H, Reber HA, Takeyama H, Hines OJ and Eibl G: Simultaneous knock-down of Bcl-xL and Mcl-1 induces apoptosis through Bax activation in pancreatic cancer cells. Biochim Biophys Acta 1833: 2980-2987, 2013.

38. Kloth MT, Catling AD and Silva CM: Novel activation of STAT $5 b$ in response to epidermal growth factor. J Biol Chem 277: 8693-8701, 2002.

39. Paukku K, Valgeirsdóttir S, Saharinen P, Bergman M, Heldin $\mathrm{CH}$ and Silvennoinen O: Platelet-derived growth factor (PDGF)-induced activation of signal transducer and activator of transcription (Stat) 5 is mediated by PDGF beta-receptor and is not dependent on c-src, fyn, jak1 or jak2 kinases. Biochem J 345: 759-766, 2000. 